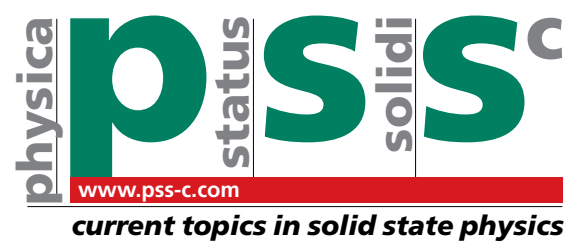

\title{
Low-temperature hollow cathode plasma-assisted atomic layer deposition of crystalline III-nitride thin films and nanostructures
}

\author{
Cagla Ozgit-Akgunn,1,2, Eda Goldenberg ${ }^{2}$, Sami Bolat $^{2,3}$, Burak Tekcan $^{2,3}$, Fatma Kayaci $^{1,2}$, Tamer Uyar $^{1,2}$, \\ Ali Kemal Okyay ${ }^{1,2,3}$, and Necmi Biyikli \\ ${ }^{1}$ Institute of Materials Science and Nanotechnology, Bilkent University, Bilkent 06800 Ankara, Turkey \\ ${ }^{2}$ UNAM - National Nanotechnology Research Center, Bilkent University, Bilkent 06800 Ankara, Turkey \\ ${ }^{3}$ Department of Electrical and Electronics Engineering, Bilkent University, Bilkent 06800 Ankara, Turkey
}

Received 9 July 2014, revised 24 October 2014, accepted 20 January 2015

Published online 16 March 2015

Keywords AlN, GaN, InN, atomic layer deposition (ALD), hollow cathode plasma

* Corresponding author: e-mail ozgit@bilkent.edu.tr, Phone: +90 312290 3551, Fax: +90 3122664365
** e-mail biyikli@unam.bilkent.edu.tr, Phone: +90 312290 3556, Fax: +90 3122664365

Hollow cathode plasma-assisted atomic layer deposition (HCPA-ALD) is a promising technique for obtaining IIInitride thin films with low impurity concentrations at low temperatures. Here we report our previous and current efforts on the development of HCPA-ALD processes for III-nitrides together with the properties of resulting thin films and nanostructures. The content further includes nylon 6,6-GaN core-shell nanofibers, proof-of-concept thin film transistors and UV photodetectors fabricated using HCPA-ALD-grown GaN layers, as well as InN thin films deposited by HCPA-ALD using cyclopentadienyl indium and trimethylindium precursors.

(๐) 2015 WILEY-VCH Verlag GmbH \& Co. KGaA, Weinheim

1 Introduction Atomic layer deposition (ALD) is a cyclic, low-temperature thin film deposition method, in which the substrate surface is exposed to sequential pulses of two or more precursors separated by evacuation and/or purging periods. When compared to other deposition techniques, ALD stands out with its self-limiting growth mechanism, which enables the deposition of highly uniform and conformal thin films with sub-angstrom thickness control. Layer-by-layer growth offered by ALD further enables the deposition of alloy thin films with well-defined compositions. These features make ALD a promising technique for the low-temperature deposition of III-nitrides and their alloys on temperature-sensitive device layers and substrates, as well as on high surface area nanostructured templates for the synthesis of III-nitride nanostructures.

Although thermal ALD (or atomic layer epitaxy, ALE) of III-nitride thin films, especially AlN, using various types of group-III precursors has been the focus of interest in the 1990s, current trend in the field of III-nitride ALD research is directed towards UV-, hot-wire- or plasma- assisted processes using metalorganic precursors [1-11]. Recently, we showed that ALD-grown III-nitride thin films may suffer from plasma-related oxygen contamination depending on the choice of $\mathrm{N}$-containing plasma gas $\left(\mathrm{N}_{2}\right.$, $\mathrm{N}_{2} / \mathrm{H}_{2}$ or $\left.\mathrm{NH}_{3}\right)[12,13]$. Therefore, as an attempt to grow O-free III-nitride thin films, we integrated an all stainless steel hollow cathode plasma (HCP) source to the ALD system, and thereby demonstrated the hollow cathode PAALD (HCPA-ALD) of wurtzite AIN, GaN and $\mathrm{Al}_{\mathrm{x}} \mathrm{Ga}_{1-\mathrm{x}} \mathrm{N}$ thin films with low impurity concentrations at $200{ }^{\circ} \mathrm{C}$ [14]. $\mathrm{GaN}$ had not been deposited in a self-limiting fashion at such low temperatures since Sumakeris et al. [15] reported the growth of GaN using a novel reactor design employing hot filaments to decompose $\mathrm{NH}_{3}$ in 1993.

In this paper, we review our previous and current efforts on the development of HCPA-ALD processes for IIInitrides together with the properties of resulting thin films and nanostructures. The content further includes nylon 6,6GaN core-shell nanofibers, proof-of-concept thin film transistors (TFTs) and UV photodetectors fabricated using 
HCPA-ALD-grown GaN layers, as well as InN thin films deposited by HCPA-ALD using cyclopentadienyl indium $(\mathrm{CpIn})$ and trimethylindium $\left(\mathrm{InMe}_{3}\right)$ precursors.

\section{Experimental details}

2.1 Hollow cathode plasma-assisted atomic layer deposition $\mathrm{AlN}, \mathrm{GaN}, \mathrm{Al}_{\mathrm{x}} \mathrm{Ga}_{1-\mathrm{x}} \mathrm{N}$, and $\mathrm{InN}$ thin films were deposited at $200{ }^{\circ} \mathrm{C}$ in a Fiji F200-LL ALD reactor (Ultratech/Cambridge NanoTech Inc.) equipped with a stainless steel HCP source (Meaglow Ltd.). Metalorganic precursors, namely trimethylaluminum $\left(\mathrm{AlMe}_{3}\right)$, trimethylgallium $\left(\mathrm{GaMe}_{3}\right), \mathrm{InMe}_{3}$ (Sigma Aldrich, SAFC Hitech), and CpIn (Strem Chemicals) were used as the groupIII source materials. $\mathrm{AlMe}_{3}$ and $\mathrm{InMe}_{3}$ were used at room temperature; whereas $\mathrm{GaMe}_{3}$ was cooled down to $6{ }^{\circ} \mathrm{C}$ using a home-made Peltier cooling system, and $\mathrm{CpIn}$ was heated to $85{ }^{\circ} \mathrm{C}$. $5 \mathrm{~N}$-grade $\mathrm{NH}_{3}, \mathrm{~N}_{2}$ and $\mathrm{H}_{2}$ plasma gases, and the carrier gas, Ar, were further purified using MicroTorr gas purifiers. Metalorganic precursor pulses and plasma gases were carried from separate lines by 30 and $100 \mathrm{sccm}$ Ar, respectively. The base pressure was $\sim 150$ mTorr. Prior to depositions, substrates were solvent cleaned. For the native oxide removal, Si substrates were further dipped into dilute hydrofluoric acid solution (HF, 2 vol.\%) for $\sim 2 \mathrm{~min}$, then rinsed with DI water and dried with $\mathrm{N}_{2}$. The details regarding to the preparation of electrospun nylon 6,6 nanofiber templates are given elsewhere [16].

2.2 Characterization methods Ellipsometric spectra of $\mathrm{AlN}, \mathrm{GaN}, \mathrm{Al}_{\mathrm{x}} \mathrm{Ga}_{1-\mathrm{x}} \mathrm{N}$, and $\mathrm{InN}$ thin films were recorded at three angles of incidence $\left(65^{\circ}, 70^{\circ}\right.$ and $\left.75^{\circ}\right)$ using a variable angle spectroscopic ellipsometer (V-VASE, J.A. Woollam Co.). Optical constants and film thicknesses of AlN, GaN, $\mathrm{Al}_{\mathrm{x}} \mathrm{Ga}_{1-\mathrm{x}} \mathrm{N}$, and $\mathrm{InN}$ were extracted using the Cauchy dispersion function and/or Tauc-Lorentz model. InN film transmission and room temperature photoluminescence (PL) measurements were carried out using a UVVIS spectrophotometer (Cary 100 Bio) and time-resolved fluorescence (Jobin Yvon, FL-1057 TCSPC), respectively. Chemical compositions and bonding states were determined by X-ray photoelectron spectroscopy (XPS) using a Thermo Scientific K-Alpha spectrometer with a monochromatized Al K $\alpha$ X-ray source. X-ray reflectivity (XRR) and grazing-incidence X-ray diffraction (GIXRD) measurements were carried out with a PANalytical X'Pert PRO MRD diffractometer using $\mathrm{Cu} \mathrm{K} \alpha$ radiation. A FEI Tecnai G2 F30 transmission electron microscope (TEM) at an operating voltage of $300 \mathrm{kV}$ was used for the imaging and selected area electron diffraction (SAED) analyses of samples. Thin film samples were prepared using an FEI Nova 600i Nanolab focused ion beam (FIB) system at an acceleration voltage of $30 \mathrm{kV}$. An atomic force microscope (AFM, Park Systems XE-100) operating in the contact mode and Quanta 200 FEG scanning electron microscope (SEM) were used to reveal surface morphologies of the deposited thin films. Samples were coated with $\sim 5 \mathrm{~nm}$ $\mathrm{Au} / \mathrm{Pd}$ alloy prior to SEM imaging.

\section{Results and discussion}

3.1 AIN, GaN and $\mathrm{Al}_{\mathrm{x}} \mathrm{Ga}_{1-\mathrm{x}} \mathrm{N}$ thin films and nanostructures In a recent study, we demonstrated the HCPA-ALD of crystalline AlN, GaN and $\mathrm{Al}_{\mathrm{x}} \mathrm{Ga}_{1-\mathrm{x}} \mathrm{N}$ thin films at low temperature (i.e., $200{ }^{\circ} \mathrm{C}$ ) using trimethylmetal precursors and $\mathrm{NH}_{3}$ or $\mathrm{N}_{2} / \mathrm{H}_{2}$ plasma [14]. Depositions carried out using non-optimized parameters resulted in AlN and GaN films with wafer-level non-uniformities $< \pm 1.5 \%$. XPS survey scans detected 2.5-3.0 and 1.5-1.7 at.\% $\mathrm{O}$ in the bulk of AlN and GaN films, respectively. C was detected only at the film surfaces and there were no $\mathrm{C}$ impurities in the bulk films as determined by XPS. Complementary secondary ion mass spectroscopy (SIMS) analyses performed on the films deposited using $\mathrm{NH}_{3}$ plasma revealed the presence of $\mathrm{O}, \mathrm{C}$ (both $<1$ at.\%) and $\mathrm{H}$ impurities in the films. GIXRD patterns indicated polycrystalline AIN and GaN thin films with wurtzite crystal structure. HCPA-ALD parameters were optimized at $200{ }^{\circ} \mathrm{C}$; trimethylmetal precursor and $\mathrm{N}_{2} / \mathrm{H}_{2}$ saturation curves evidenced the self-limiting growth of AlN and GaN at this temperature. AlN exhibited linear growth with a slight nucleation delay. The growth per cycle (GPC) of AlN was high (i.e., $\sim 1.0 \AA$ ). In the case of GaN, substrate-enhanced growth was observed. The GPC was found to be $0.22 \AA$ for the 900-cycle GaN deposition. $59.2 \mathrm{~nm}$ thick AlN and $20.1 \mathrm{~nm}$ thick GaN thin films deposited using optimized process parameters were characterized using spectroscopic ellipsometry, high-resolution XPS, GIXRD, XRR, and AFM. Compositions of the $\mathrm{Al}_{\mathrm{x}} \mathrm{Ga}_{1-\mathrm{x}} \mathrm{N}$ thin films obtained via digital alloying were determined by Vegard's rule as 0.68 (AlN:GaN = 1:3), $0.95(1: 1)$, and $0.96(3: 1)$ using the $c$ lattice parameters. Refractive index values of the $\mathrm{Al}_{\mathrm{x}} \mathrm{Ga}_{1-\mathrm{x}} \mathrm{N}$ thin films decreased from 2.03 to 1.96 as the $\mathrm{Al}$ content increased from 0.68 to 0.96 . The adjustability of band edge values with alloy composition has been confirmed by optical transmission measurements, which indicated absorption-free films whose optical band edge values shift to lower wavelengths with increasing $\mathrm{Al}$ content.

In order to demonstrate the feasibility of HCPA-ALD method for the preparation of three-dimensional (3D) IIInitride nanostructures, we deposited GaN on organic nanofibers prepared by electrospinning. 1000 cycles were deposited on electrospun nylon 6,6 nanofibers having $\sim 70 \mathrm{~nm}$ average fiber diameter at $200{ }^{\circ} \mathrm{C}$ using $\mathrm{GaMe}_{3}$ and $\mathrm{N}_{2} / \mathrm{H}_{2}$ plasma. TEM image of the resulting nylon $6,6-\mathrm{GaN}$ coreshell nanofibers is given in Fig. 1. As seen from this figure, conformal GaN coatings with uniform wall thickness along the fiber axis were obtained. High-resolution TEM images and SAED pattern confirmed the polycrystalline structure of deposited GaN layer. 


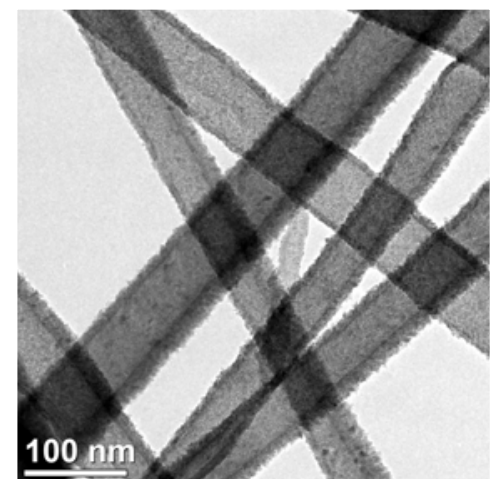

Figure 1 Representative bright-field TEM image of nylon 6,6GaN core-shell nanofibers

3.2 (Opto)electronic device applications of GaN thin films Recently, we have reported GaN-based transistors with the lowest thermal budget reported so far [17]. We used HCPA-ALD-grown GaN layers in TFTs having bottom gate configuration, where gate stack was formed on a highly doped $\mathrm{Si}(1-5 \mathrm{~m} \Omega \mathrm{cm})$ substrate at a single ALD step performed at $200{ }^{\circ} \mathrm{C}$ including the deposition of $\mathrm{Al}_{2} \mathrm{O}_{3}(77 \mathrm{~nm})$ and $\mathrm{GaN}(11 \mathrm{~nm})$ as the insulator and semiconductor, respectively. Output characteristics of the device revealed the clear saturation and pinch off of the drain current with the increased drain voltage. Transfer characteristics showed that the fabricated device has an $\mathrm{I}_{\mathrm{ON}} / \mathrm{I}_{\mathrm{OFF}}$ of $2 \times 10^{3}$. Threshold voltage, subthreshold swing and channel mobility of the device were found to be 11.8 $\mathrm{V}, 3.3 \mathrm{~V} / \mathrm{dec}$ and $0.025 \mathrm{~cm}^{2} / \mathrm{Vs}$, respectively. The effect of the positive gate bias stress on the threshold voltage was also investigated and threshold voltage shift lower than $8 \mathrm{~V}$ after a bias of $2.5 \mathrm{MV} / \mathrm{cm}$ for $1000 \mathrm{~s}$ was obtained. We also fabricated proof-of-concept metal-semiconductor-metal (MSM) UV photodetectors using HCPA-ALD-grown GaN layers [18]. Electrical current-voltage measurements showed low dark current voltages as low as $14 \mathrm{pA}$ at $30 \mathrm{~V}$ reverse bias. Optical characteristics of the devices were also studied. Devices showed 15x rejection ratio comparing UV/VIS wavelengths. Responsivity spectrum was in agreement with optical absorption spectrum of HCPAALD-grown GaN films. These devices can pave the way for temperature sensitive processes such as flexible optoelectronics as well as CMOS integration of such devices.

3.3 $\ln \mathbf{N}$ thin films 800 cycles $\mathrm{InN}$ were deposited on $\mathrm{Si}$ (100), Si (111) and HCPA-ALD-grown AlN/Si (100) substrates at $200{ }^{\circ} \mathrm{C}$ using $1 \mathrm{~s} \mathrm{CpIn/10} \mathrm{s} \mathrm{Ar} \mathrm{purge} / 40 \mathrm{~s}$, $50+50 \mathrm{sccm}, 300 \mathrm{~W} \mathrm{~N}_{2} / \mathrm{H}_{2}$ plasma/10 s Ar purge. The deposition was done twice, as the $4^{\text {th }}$ and $59^{\text {th }}$ runs following the integration of HPC source. Film deposited on Si (100) substrate as a result of the $4^{\text {th }}$ run was found to be composed of tetragonal In $(t-\mathrm{In})$ and cubic $\mathrm{In}_{2} \mathrm{O}_{3}\left(c-\mathrm{In}_{2} \mathrm{O}_{3}\right)$ phases; whereas for the sample deposited on AlN/Si (100) substrate, GIXRD results indicated the existence of wurtzite (hexagonal) $\mathrm{InN}(h$-InN) phase in addition to the $t$-In and $c-\operatorname{In}_{2} \mathrm{O}_{3}$. Films deposited as a result of the $59^{\text {th }}$ run, on the other hand, were identified as polycrystalline, singlephase $h$-InN irrespective of the substrate (Fig. 2). The formation of $t-\operatorname{In}$ and $c-\operatorname{In}_{2} \mathrm{O}_{3}$ phases is believed to be due to the residual water in the deposition chamber, which was scavenged by the metalorganic pulses during the runs between the two identical depositions. XRR results obtained from $h$-InN thin film deposited on $\mathrm{Si}$ (111) substrate indicated negligible thickness and a quite low mass density for this film. Accordingly, surface morphology studies performed using AFM evidenced the formation of InN islands on Si (111). For the film deposited on AlN/Si (100) substrate, thicknesses of the $\mathrm{InN}$ and $\mathrm{In}_{2} \mathrm{O}_{3}$ layers were estimated to be 34.87 and $0.08 \mathrm{~nm}$, respectively. However, mass density of the deposited InN was found to be 2.89 $\mathrm{g} / \mathrm{cm}^{3}$, which is very low compared to the recognized value of $6.81 \mathrm{~g} / \mathrm{cm}^{3}$ [19]. XRR also revealed the surface roughness for this film as $3 \mathrm{~nm}$. AFM analysis was in good agreement with these results, and indicated a 3D layer, which is composed of coalesced small islands and a considerable volume of voids, having $3.14 \mathrm{~nm}$ rms surface roughness as measured from a $1 \mu \mathrm{m} \times 1 \mu \mathrm{m}$ scan area.

Another set of $\mathrm{InN}$ thin films were deposited on $\mathrm{Si}$ (100) substrates at $200{ }^{\circ} \mathrm{C}$ using $\mathrm{InMe}_{3} .1000$ cycles were deposited, where one HCPA-ALD cycle was $0.03 \mathrm{~s}$ $\mathrm{InMe}_{3} / 10 \mathrm{~s}$ Ar purge $/ 40 \mathrm{~s}, 50+50 \mathrm{sccm}$ (or $50 \mathrm{sccm}$ ), 300 $\mathrm{W} \mathrm{N} \mathrm{N}_{2} / \mathrm{H}_{2}$ (or $\mathrm{N}_{2}$ ) plasma/10 s Ar purge. GIXRD results indicated polycrystalline thin films; the film deposited using $\mathrm{N}_{2} / \mathrm{H}_{2}$ plasma was found to be composed of $h$-InN and $t$-In phases, whereas the film deposited using $\mathrm{N}_{2}$ plasma was identified as single-phase $h$-InN. Polycrystalline structure of this $h$-InN film was further confirmed by highresolution TEM and SAED. Thickness, mass density and surface roughness values of the films deposited using $\mathrm{N}_{2} / \mathrm{H}_{2}$ and $\mathrm{N}_{2}$ plasma were estimated using XRR as 59.3 and $42.7 \mathrm{~nm}, 4.52$ and $6.56 \mathrm{~g} / \mathrm{cm}^{3}$, and 5.58 and $2.06 \mathrm{~nm}$, respectively. Thickness values were further confirmed by spectroscopic ellipsometry measurements. The surface roughness values obtained using XRR were in good agreement with the corresponding surface morphologies (Fig. 3). XPS survey scans obtained after $60 \mathrm{~s}$ of Ar ion etching indicated that there were no $\mathrm{C}$ impurities in the films. For the film deposited using $\mathrm{N}_{2}$ plasma, there were no $\mathrm{O}$ impurities either; however $\sim 21$ at. $\% \mathrm{O}$ was detected in the film deposited using $\mathrm{N}_{2} / \mathrm{H}_{2}$ plasma. This high oxygen concentration might be associated with the 3D surface oxide layer. Optical constants (n, k at $630 \mathrm{~nm}$ ) of the film deposited using $\mathrm{N}_{2}$ plasma were estimated to be 2.55 and 0.30 , which agree with the reported values for the same wavelength range [20]. InN films deposited using $\mathrm{N}_{2} / \mathrm{H}_{2}$ and $\mathrm{N}_{2}$ plasma exhibited relatively high transmission in the IR and $\sim 45 \%$ transmission in the VIS region. UV-VIS T\% measurements indicated a high band gap of $>2 \mathrm{eV}$, which 


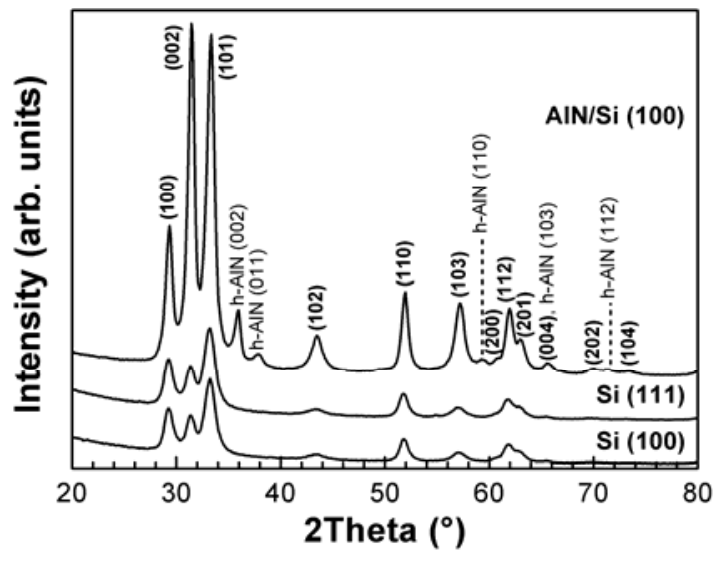

Figure 2 GIXRD patterns of InN thin films deposited at $200{ }^{\circ} \mathrm{C}$ on various substrates using CpIn and $\mathrm{N}_{2} / \mathrm{H}_{2}$ plasma.
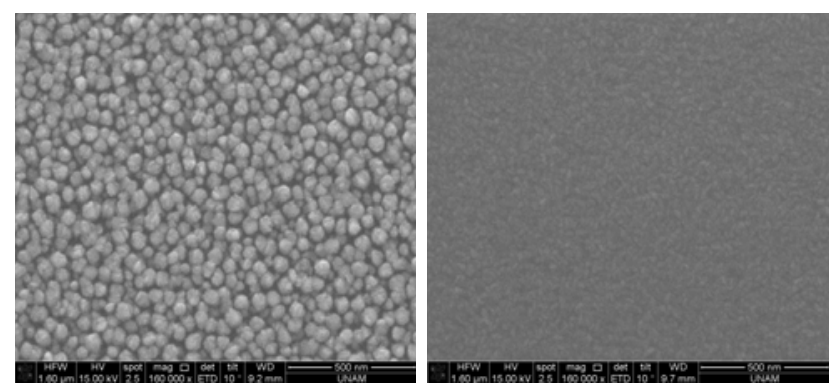

Figure 3 Plan-view SEM images of InN films deposited at $200{ }^{\circ} \mathrm{C}$ on $\mathrm{Si}(100)$ substrates using $\mathrm{InMe}_{3}-\mathrm{N}_{2} / \mathrm{H}_{2}$ plasma (left) and $\mathrm{InMe}_{3}-\mathrm{N}_{2}$ plasma (right) processes.

was also confirmed by PL measurements, probably due to the defect- and (quantum) size-related effects [21].

Although the reason of island formation in HCPAALD processes using CpIn or $\mathrm{InMe}_{3}$ and $\mathrm{N}_{2} / \mathrm{H}_{2}$ plasma has not been clarified yet, it is worth noting that a similar morphology was reported for InN films grown by ALE using $\mathrm{InCl}_{3}$ and $\mathrm{NH}_{3}$ [22]. Recently, Nepal et al. [11] deposited InN thin films having either a novel cubic and/or a hexagonal structure by PA-ALE using $\mathrm{InMe}_{3}$ and $\mathrm{N}_{2}$ plasma. In the present study, the film deposited using $\mathrm{N}_{2}$ plasma only has shown to possess superior properties compared to those deposited using a mixture of $\mathrm{N}_{2}$ and $\mathrm{H}_{2}$ plasma. The presented data suggest that addition of $\mathrm{H}_{2}$ to the plasma gas has a profound effect on the properties of deposited InN films, which are known to be quite susceptible to plasma-related deterioration during their growth [21].

4 Conclusions Here we reviewed our previous and current efforts on the development of PA-ALD processes for III-nitride thin films and their alloys using a HCP source for creating reactive $\mathrm{N}$ species. We successfully deposited polycrystalline wurtzite $\mathrm{AlN}, \mathrm{GaN}$ and $\mathrm{Al}_{\mathrm{x}} \mathrm{Ga}_{1-\mathrm{x}} \mathrm{N}$ thin films with low impurity concentrations at temperatures as low as $200{ }^{\circ} \mathrm{C}$ using metalorganic group-III precursors.
The feasibility of HCPA-ALD technique for the preparation of 3D III-nitride nanostructures was demonstrated via nylon 6,6-GaN core-shell nanofibers. Proof-of-concept TFTs and MSM UV photodetectors, which were fabricated using HCPA-ALD-grown GaN layers, were also presented. Preliminary experiments have shown that $\mathrm{InMe}_{3}-\mathrm{N}_{2}$ plasma HCPA-ALD process on a Si (100) substrate results in polycrystalline wurtzite InN thin film with low impurity concentrations and a smooth surface morphology.

Acknowledgements This study was supported by the State Planning Organization (DPT) of Turkey through the National Nanotechnology Research Center (UNAM) Project. A. K. O. and N. B. acknowledge the financial support from TUBITAK (Project \#112M004 and 112M482). M. Guler from UNAM is acknowledged for TEM imaging.

\section{References}

[1] X. Liu, S. Ramanathan, E. Lee, and T. E. Seidel, Mater. Res. Soc. Symp. Proc. 811, 11 (2004).

[2] D. Eom, S. Y. No, C. S. Hwang, and H. J. Kim, J. Electrochem. Soc. 153, C229 (2006).

[3] K.-H. Kim, N.-W. Kwak, and S. H. Lee, Electron. Mater. Lett. 5, 83 (2009).

[4] M. Bosund, T. Sajavaara, M. Laitinen, T. Huhtio, M. Putkonen, V.-M. Airaksinen, and H. Lipsanen, Appl. Surf. Sci. 257, 7827 (2011).

[5] M. Alevli, C. Ozgit, I. Donmez, and N. Biyikli, J. Cryst. Growth 335, 51 (2011).

[6] C. Ozgit, I. Donmez, M. Alevli, and N. Biyikli, Thin Solid Films 520, 2750 (2012).

[7] Y.-R. Shin, W.-S. Kwack, Y. C. Park, J.-H. Kim, S.-Y. Shin, K. I. Moon, H.-W. Lee, and S.-H. Kwon, Mater. Res. Bull. 47, 790 (2012).

[8] W. Lei and Q. Chen, J. Vac. Sci. Technol. A 31, 01A114 (2013).

[9] A. P. Perros, H. Hakola, T. Sajavaara, T. Huhtio, and H. Lipsanen, J. Phys. D, Appl. Phys. 46, 505502 (2013).

[10] N. Nepal, S. B. Qadri, J. K. Hite, N. A. Mahadik, M. A. Mastro, and C. R. Eddy, Jr, Appl. Phys. Lett. 103, 082110 (2013).

[11] N. Nepal, N. A. Mahadik, L. O. Nyakiti, S. B. Qadri, M. J. Mehl, J. K. Hite, and C. R. Eddy, Jr., Cryst. Growth Des. 13, 1485 (2011).

[12] C. Ozgit, I. Donmez, M. Alevli, and N. Biyikli, J. Vac. Sci. Technol. A 30, 01A124 (2012).

[13] C. Ozgit-Akgun, I. Donmez, and N. Biyikli, ECS Trans. 58, 289 (2013).

[14] C. Ozgit-Akgun, E. Goldenberg, A. K. Okyay, and N. Biyikli, J. Mater. Chem. C 2, 2123 (2014).

[15] J. Sumakeris, Z. Sitar, K. S. Ailey-Trent, K. L. More, and R. F. Davis, Thin Solid Films 225, 244 (1993).

[16] C. Ozgit-Akgun, F. Kayaci, I. Donmez, T. Uyar, and N. Biyikli, J. Am. Ceram. Soc. 96, 916 (2013).

[17] S. Bolat, C. Ozgit-Akgun, B. Tekcan, N. Biyikli, and A. K. Okyay, Appl. Phys. Lett. 104, 243505 (2014).

[18] B. Tekcan, C. Ozgit-Akgun, S. Bolat, N. Biyikli, and A. K. Okyay, Opt. Eng. 53, 107106 (2014).

[19] M. E. Levinshtein, S. L. Rumyantsev, and M. S. Shur, Properties of Advanced Semiconductor Materials (Wiley, New York, 2001), p. 49. 
[20] L. F. Jiang, W. Z. Shen, H. F. Yang, H. Ogawa, and Q. X. Guo, Appl. Phys. A 78, 89 (2004).

[21] K. S. A. Butcher and T. L. Tansley, Superlattices Microstruct. 38, 1 (2005).
[22] K. Higuchi, A. Unno, and T. Shiraishi, Mater. Res. Soc. Symp. Proc. 222, 169 (1991). 